\title{
How Do Elementary Childhood Education Teachers Perceive Robotic Education in Kindergarten? A Qualitative Study
}

\author{
Feray Uğur-Erdoğmuş ${ }^{*}$ \\ Department of Computer Technology, Amasya University, Amasya, Turkey \\ ORCID: 0000-0002-9401-3405
}

\begin{tabular}{ll}
\hline \hline Article history & Robotic education is a popular topic in recent years. There are robotic \\
Received: & education courses from pre-K to K-12 and these courses claim that they \\
& support STEM education. However, the teacher's perception of these \\
Received in revised form: & activities and needs for this education is the missing part of the chain. \\
30.12 .2020 & The aim of this study to find out the perceptions and suggestions of early \\
& childhood teachers about robotic education in kindergartens. This is a \\
Accepted: & qualitative phenomenological study. Ten early childhood education \\
30.12 .2020 & (ECE) teachers were the participants of this study. A semi-structured \\
Key words: & interview form was developed and in-depth interviews were conducted to \\
\hline Robotic education; & collect qualitative data. After that codes and themes were defined through \\
Kindergarten; & the content analysis process. The results of this study showed that ECE \\
& teachers have a positive attitude towards robotic education in \\
& kindergarten. The current status of kindergarten, perceived \\
& advantages/disadvantages of robotic education, and ideal robotic \\
& education were the emerged themes during data analysis. According to \\
& results, ECE teachers thought that there are many needs like teacher \\
& training, materials, curriculum, infrastructure, technical support, and \\
& parent education for implementing robotic education properly in \\
& kindergartens. Also, teachers underlined that robotics education could be \\
& beneficial for motivation, knowledge, thinking skills, development, and \\
& psychomotor skills of children. Results also revealed ECE teachers' \\
& suggestions about ideal robotic education in kindergartens. Suggestions \\
& for future studies and practitioners were also included.
\end{tabular}

\section{Background of the Study}

Education is an important issue for society, economy, and of course countries. Students are the future citizens of the countries and their education will affect the countries' future. That is why sometimes according to the needs of the countries, educational strategies change. According to US Bureau of Labor statistics, between 2009 and 2015 employment in STEM occupations in the USA increased $10.2 \%$ and occupation in computer-related areas is expected to grow by $12.5 \%$ from 2014-2024 (Fayer, Lacey, \& Watson, 2017). That is why STEM education stays in the spotlight and receives huge financial support in countries like the USA, UK, and Australia and this attention rapidly increased from the late1990s to 2015 (Blackley \& Howell, 2015). STEM is the short form of Science, Technology, Engineering, and Mathematics and emphasizes teaching these subject areas in an integrated curriculum. For

\footnotetext{
*Correspondency: ferayugur@gmail.com, feray.erdogmus@amasya.edu.tr
} 
most people, it is understood as only science and mathematics, but a full understanding of STEM education should increase students' comprehension of how things work and make improvements in technology usage (Bybee, 2010). Sullivan and Bers (2016) also criticized neglection of technology and engineering sides of STEM education and underlined that robotic education may be a solution to this problem.

Using robots in the learning process may be defined as robotic education. Robots are developed by using advanced technology and offer a concrete and physical demonstration of learning outcomes (Mubin, Stevens, Shahid, Mahmud, \& Dong, 2013). The role of the robots in the educational setting changes according to instructional purposes. Robots can be used as a teacher, material, or peer in the instructional setting (Mubin et al., 2013). Moreover, they may be categorized as social robots and robotic kits (Jung \& Won, 2018). In the literature, if robots are used as peer or tutor, they are called social robots and robotic kits are the use of robots as material and mostly to teach programming skills in different age groups (JaipalJamani \& Angeli, 2017; Sullivan \& Bers, 2016; Taylor, Vasquez, \& Donehower, 2017).

In the market there are many robotic kits for education, and they are generally used to teach programming skills to learners. Thesemay be beneficial in making programming instruction more concrete and enjoyable. In the literature there are many experimental studies related to positive effects of using robotic kits in education. For example, Lin and Kuo (2010) used robotic kits in programming education of primary and secondary school students and reported improvement in programming skills. In another experimental study, using robotic kits has a positive effect on students' attitudes and problem-solving skills (Sohn, 2014). Similarly, Sullivan (2008) find out that robotic activities have a positive effect on secondary school student's scientific process skills and on comprehending systems skills. Noh and Lee (2020) find out in programming education using robots increase computational thinking skill and students' creativity. Moreover, using robotic kits significantly increased girls' technology usage (Beisser, 2006), and enhanced interest levels of girls in engineering (Sullivan \& Bers, 2019). In another study, researchers stated that high school students who used robotic kits find different and creative solutions to problems (Barak \& Zadok, 2009). Like these studies, according to a literature review study, robotic education has the potential to improve computational thinking skills and social skills in K-12 (Ioannou \& Makridou, 2018). Although there are studies in favor of robotic education, there are studies that show no significant enhancement in learning (Benitti, 2012). One-year experimental study results revealed that robotic education has no effect on pupil's performance (Lindh \& Holgersson, 2007). Moreover, experimental studies related to robotic education have problems like small sample sizes and non-experimental research studies are mostly conducted in elementary and secondary schools, and some studies show no significant difference in mathematical learning (Zhong \& Xia, 2020).

As there are limited studies on using robots in kindergarten for educational purposes, there exists a huge potential for STEM fields interest of students and in promoting project-based learning (Cherniak, Lee, Cho, \& Jung, 2019). With robotic education children can learn basic programming skills and robotics (Sullivan \& Bers, 2016), improve programming skills and enhance abilities in planning and controlling complex tasks (Di Lieto et al., 2017), enhance sequencing skills (Kazakoff \& Bers, 2014), and an increase in the interest of girls in engineering can be possible (Sullivan \& Bers, 2019). In light of these studies, robotics in kindergarten can be beneficial for children. However, the tool is not the only aspect that results in enhancements in learning outcomes and enhancements in some skills. As criticized, many educational technology researchers focused on tools rather than real problems in 
education (Reeves \& Reeves, 2015) and there would be problems for teachers with integrating coding and also with building pedagogy of robotic education for small ages (Manches \& Plowman, 2015).

Besides, teachers are the key in applying new technologies and new approaches in class. As Joo, Park, and Kim underlined "teacher self-efficacy, perceived ease of use and perceived usefulness of using technology affected teachers' intention to use technology" (2018, p.48). Moreover, personal innovativeness is also important in teachers' technology acceptance (Mazman Akar, 2019) and similarly, kindergarten teachers' innovativeness and subjective norm have an important role in the decision to use technology in class or not (Jeong \& Kim, 2017). Not surprisingly factors that affect teachers' technology acceptance vary according to the research context. For example, according to Wong's "pragmatic consideration of facilitating conditions" is the dominant factor in planning to use technology in Hong Kong (2016, p.313).

Base on the above studies, robotic education in kindergarten is an important issue and to apply it effectively teacher's perspective has a critical place. Hence, this study aims to find out the perception of early childhood teachers about robotic education. Research question of this qualitative study was "What are the perceptions of kindergarten teachers about robotic education?".

\section{Method}

This is a qualitative research study that employed a phenomenological approach. Phenomenological studies were conducted to explore "various reactions to, or perceptions of a particular phenomenon" (Fraenkel, Wallen \&Hyun, 2015, p. 430). The focus of the phenomenological study is the phenomenon that we are aware of, but we do not comprehend deeply and in detail (Yıldırım\& Şimşek, 2016). Robotic education in kindergarten phenomenon is the focus of this study and the kindergarten teachers' perception of this phenomenon investigated in this study because the purpose of this study was to understand the kindergarten teachers' perceptions of robotic education.

\section{Participants}

In this study, purposeful sampling was used to decide the participants. In this sampling strategy researchers select people deliberately to comprehend the main phenomenon (Creswell, 2012). Participants selected form the kindergarten teachers who encounter robotic education applications in kindergarten from the social media or other media devices but never apply robotics in their classes. 10 volunteering in-service kindergarten teachers who have information about robotic education applications in kindergarten and have experience in kindergarten teaching were the participants of this study. 2 of the participants were male and 8 of them were female. The average experience of the participants in teaching is 3.2 years.

\section{Data Collection and Analysis}

The in-depth interview technique was used to collect data in this study. The purpose of interviewing is to understand participants' thoughts or feelings about a phenomenon, and it is an important data collection technique for qualitative studies (Fraenkel, Wallen \&Hyun, 2015). A semistructured interview (see Table 1 for the questions and probing questions) form was developed by the researcher and interviews were conducted. After that interview 
schedule was established and interviews were conducted face-to-face at the kindergartens that interviewees were teaching.

In the data analysis process, Creswell's (2012) six-step for analyzing and interpreting qualitative data were applied to qualitative data. According to his procedure, first, data were prepared by doing transcription and ensuring anonymity in naming the files and data decided to be analyzed by the computer. Second, data was read and reread by the researcher to get a general sense, and then the data were coded. Third, after the coding process, codes are reduced and categorized under themes. Fourth, the researcher decided on how to visualize the findings. Fifth, findings were interpreted and finally accuracy of findings was validated.

In this study, first, all the interview records were converted into text and named anonymously. Then, the researcher read and reread the interview documents to obtain the general sense and grasp the general tone of the interviewees. After that, the coding process started and through in-depth reading and analysis codes were assigned. The coding process is iterative and there can be refinements through the coding process (Fraenkel, Wallen \&Hyun, 2015). After that codes were analyzed, and redundant codes were merged or deleted. Later themes were created and a hierarchical structure between codes was formed. Then, tables and figures that best represent the findings were designed. Finally, findings were interpreted, and to ensure the trustworthiness of the study member checking, the thick description, and inter-coder reliability methods were used.

\section{Findings}

The findings of this study are presented below according to themes that emerged during the data analysis. These themes are ideal robotic education in kindergarten, possible advantages/disadvantages, and the status of kindergartens.

\section{Current status of kindergarten}

The current status of kindergarten was the first theme that emerged during data analysis. Experience and attitudes of teachers, student characteristics, available resources, and needs were the codes under these themes. According to the results, none of the participants had experience with robotic education in kindergarten. All of the participants know something about robotic education, but they never held a robotic education activity in their classes. All of them know the coding activities in kindergartens and one of them applies coding activity sheets in school. According to the results, nine of the participants thought that robotic education should be a part of the kindergarten curriculum and it is a need for today's children. For example, T3 states his/her positive position as "In today's age, these things [programming and robotic education] are more and more prominent...started to come out as technology progressed. I think our children should definitely start coding? before school to keep up with these things". However, one of the participants hesitated about robotic education because of the possible negative effects of using technology at an early age. S/he states that "But I am not sure if it [robotic education] is necessary for the pre-school period. Because I am not in favour of preschool children being so involved with computers and technology with the exception of the age group of 5, it may be possible in the kindergarten group".

Then, under the student characteristic code, there were four subcodes; attention span, creativity, social interaction, and use of technology. Three of the participants highlighted that children have a short attention span. For example, T9 states that "Children have very short attention spans due to their age". Similarly, T6 underlined the attention span issue in his/her 
word as "Attention in children is a problem, we are already troubled now. We have trouble in concentration. We are experiencing great difficulty". Secondly, two of the participants emphasized that children are creative. For example, T6 states that "I have children with a lot of creativity and productivity". Thirdly, one of the teachers highlighted that some of the children are social learners and like to do activities with friends. Finally, under the use of technology code, one of the participants underlines the technology usage frequency of children. T5 underlined this issue as "First of all, children use tablets and computers a lot at this time". Besides student characteristics, available resources in robotic education is also an important criterion. Four of the participants states that there are robotic kits and some printed materials for kindergarten students. However, one of the participants criticized that materials do not include target age group information.

Teachers also underlined needs for kindergartens for robotic education. Under needs code, teacher training, materials, curriculum, trained technical personnel, infrastructure, technical support, and parent education were the subcodes. Nine of the participants highlighted 18 times that early childhood teachers need the training to apply robotic education. They criticized their teacher education program at university, and they underlined that they did not take courses about robotic kits or programming education in kindergarten. For example, T10 noted that "After all, I don't know much about this, and it seems like a necessary thing in our age. After all, this education could have been given to me at the university. I should have encountered this before". Moreover, they underlined that they need in-service training programs about robotic education related to the pre-school group. For example, T4 emphasized that "But in the first step of the job we should be informed about this by experts." Similarly, T7 underline this issue in his/her words as "So it is always better to train the teacher first and then put the project into practice". T9 also clearly underlined that "Preschool teachers should be trained on this subject". Moreover, they highlighted that this education training should be given by teachers who were educated in robotic education. T1 underlines this issue as "I think it is more appropriate for the education to be given programmatically by people who know the subject well."

Besides, needs related to materials also emerged as a code. Six of the participants stated that they need materials for robotic education. Four of them stated that they need robotic kits. For example, T4 states this need as "Resources can be increased for dissemination. National Education may provide us material support for this. ... even if it sends one or two [robotic kits] to our school, we can use these by exchanging them between our classes" Another material that was stated as a need was printed materials. Two of the participants stated that they need printed materials for robotic education. According to the findings, there were also needs related to the curriculum. Three of the participants stated that robotic education should be planned and included in the early childhood curriculum. For example, T7 stated that "It has to be entered as part of the curriculum once so that we can put it into practice. Without the curriculum, there is no chance for this to be implemented since we cannot keep the child in pre-school education outside of school with a course or something."

Under the needs code infrastructure, technical support, and parent education were the codes. Two teachers stated that there are needs related to technical infrastructures like smart boards and technical equipment. One teacher stated that they need technical support in school and one of the teachers added that parents should be trained about robotic education in kindergarten. S/he underlined this issue in her/his own words like "After the information is given to us, it is necessary for family education to come into play. Child education should be given importance after the family. I see the child as Step 3. First teacher, second-level parent, 
third-level child."

\section{Advantages and Disadvantages of robotic education}

According to the data analysis result, one of the emerged themes was the advantages/disadvantages of robotic education. Teachers stated many possible advantages and some disadvantages that may occur if robotic education is added to the curriculum of kindergartens. Results show that teachers mostly have positive expectations about robotic education. All of the participants stated the advantages of robotic education. According to findings, five codes emerged and four of these codes have sub-codes. Motivation, knowledge, thinking skills, development, and psychomotor skills were the codes under this theme. Hierarchical representation of these themes and the number of participants that mentioned these advantages presented in Figure 1.

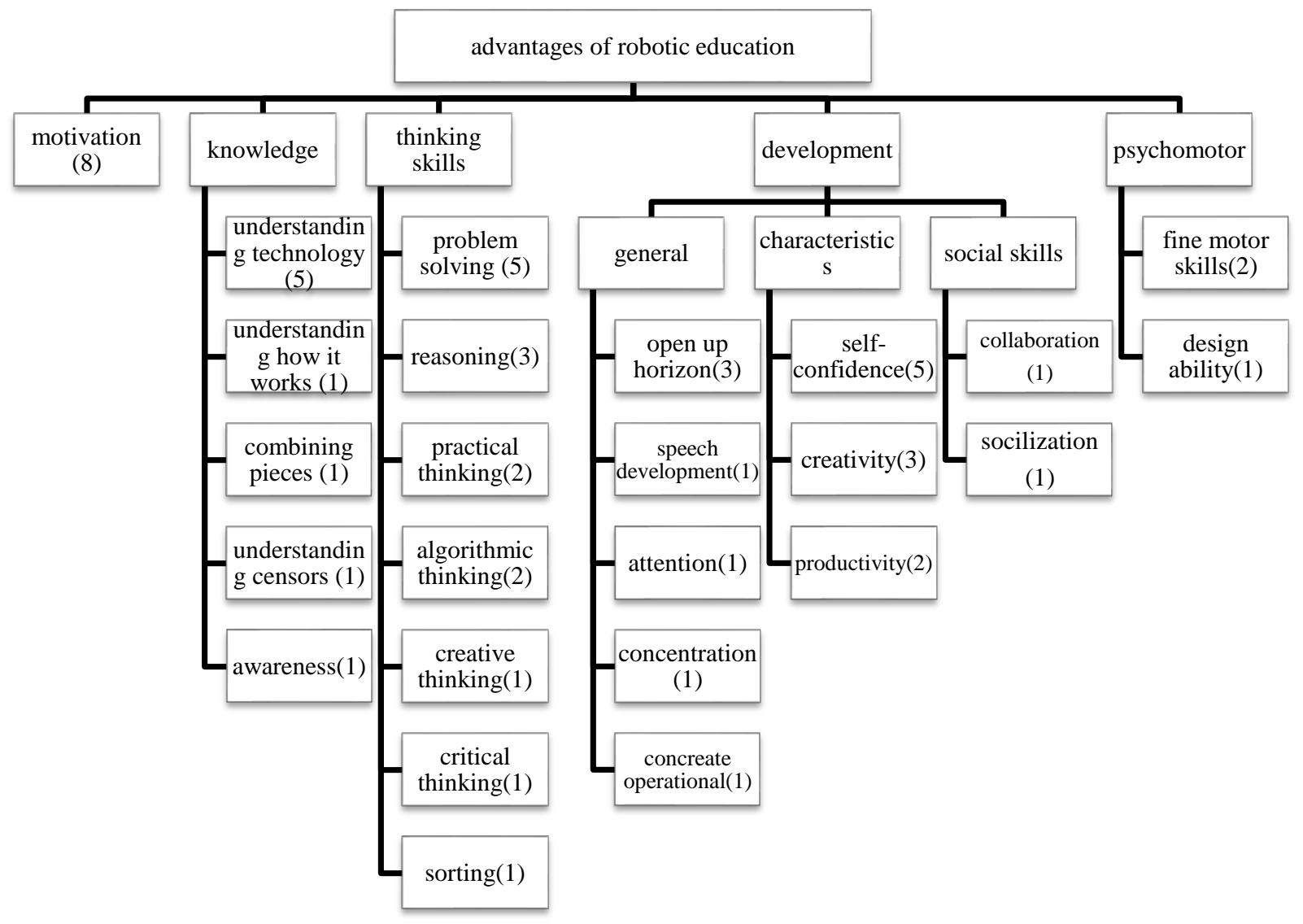

Figure 1. Possible advantages of robotic education in kindergarten

As it is seen in Figure 1, motivation was the most frequently stated advantage of robotic education. Eight of the teachers stated that robotic education would increase the motivation of the students. T3 explained this issue in his/her words as "They will be very interested, they say 'Wow'. In the process of doing it [robot], at that time they gain the objective that you want to fulfil. Then they will wonder how the product comes out. Of course, it will be more encouraging for them to progress by curiosity's sake." Similarly, T4 states that "I don't think we will ever try to include them in the activity. I always think they will start by saying 'Ah!'. I think they won't get bored".

Also, teachers stated some expected cognitive developments in robotic education. These 
expectations were categorized under the knowledge code. Sub-codes of these codes were understanding technology, understanding how it works, combining pieces, understanding sensors, and awareness. Five of the teachers underline that robotic education would help students in understanding technology, how it works, and what can somebody do with technology. For example, T1 explained his/her ideas as "He can learn about the technology that can make the machines which he sees in the cartoons or his dreams. Getting to know the technology ... what can be done and what can be achieved with a computer". Moreover, T1 also underlines that this education could help children to understand how something works. He states that "So, while looking at everything around him, he will be able to understand what is done and how, with what logic it is done, with what logic it works".

As seen in Figure 1 another code that emerged under this theme was thinking skills. Nine of the participants stated that robotic education in kindergarten could help to develop some thinking skills. These thinking skills were problem-solving, reasoning, practical thinking, algorithmic thinking, creative thinking, critical thinking, and sorting. Five of the participants stated that robotic education could teach and increase the problem-solving skills of children. For example, T2 states that "I think that this [robotic education] is very important for a child's problem-solving skill”. Also, T5 states that "...I think that even when the educated child has problems with his friends, he can easily solve it among themselves. I think they will discover a shorter way for problems to reach their consequences".

Another advantage that was underlined by participants was developmental benefits and categorized under development code. As seen in Figure 1, the development code has 3 subcodes (general, characteristics, and social skills) and under these codes, there were also subcodes. Firstly, robotic education has potential developmental benefits on opening up a child's horizon, speech development, attention, concentration, and concrete operational state. Three of the participants stated that this education might open up a child's horizon and increase children's knowledge about robotics and technology. For example, T1 clearly states that "It will open up a child's horizon". Besides, T6 underlines attention and states that "Now, we are new to this subject, I can say these with a prediction. Seems like it can be useful to them in terms of focusing their attention." Moreover, one of the participants thought that this education might improve concentration ability of the children and another one thought that it might help them to operate as if they were at concrete operational state (Huitt \& Hummel, 2003). Secondly, participants stated that there can be developments in the characteristics of children in terms of self-confidence, creativity, and productivity. As it is seen in Figure 1, five of the participants stated that robotic education would have possible effects on selfconfidence. T5 underlines this possibility as "Their self-confidence is improved. [They can say] I can succeed now; I can solve my problems myself. Here self-confidence is built." Moreover, three of the teachers underlined creativity as a positive outcome of robotic education. T6 explained this as "[Robotic education is] something that can improve their creativity. We give the materials, and we say what can we do... Here, their creativity also improves, and their thinking skills develop. It can be useful in this sense". The last sub-code under this theme was social skills. Two of the participants underline these social skills. One of them stated that robotic education may increase collaboration skills and the other one emphasized socialization.

The last code under the advantages of robotic education was psychomotor. Under this theme participants' opinions about possible psychomotor skills that robotic education may increase were categorized. Two of the participants stated that robotic education may develop the fine motor skills of children. Besides one of the participants underlined that robotic education 
could develop the design ability of students.

According to findings, there were some stated disadvantages of robotic education in kindergarten. These were categorized under the disadvantages code. Two of the participants stated that the cost of the robotic kits was a problem for this education. For example, T1 underlined the cost as "Now these involve sets. Every school cannot afford these sets. as they are pretty expensive". One of the participants emphasized that the number of students should be limited and crowded classrooms constitute a problem. Also, one of the participants stated that robotic education in kindergarten may negatively affect socialization in the classroom.

\section{Ideal robotic education}

According to findings, ECE teachers have perceptions about ideal robotic education in kindergarten. Under this theme, four subthemes emerged during the analysis. These subthemes were teacher characteristics, teaching method, content, and context. Under the teacher characteristics code, three participants underlined that an ideal robotic education teacher should have content knowledge, i.e., knowledge about robotic kits and other soft and hard skills to teach these kits. For example, T1 states that "The friend [teacher] who will do the Robotics Training must comprehend the subject area." Moreover, being inquiry-minded $(f=2)$, being a lifelong learner $(f=2)$, and being a researcher $(f=1)$ are the characteristics that participants underlined. Besides this two of the participants emphasized that a technology teacher should teach robotic education in the kindergarten instead of the ECE teachers.

Participants also have various suggestions about the proper teaching method for robotic education in kindergarten. The most suggested teaching method was teaching robotic education with games. Seven participants stated 13 times that this method is the best way to teach robotic education in kindergarten. For instance, T9 states that "Play is a more effective method for children, i.e. the age group I am interested in. I would teach it to the children by gamifying it ". Similarly, T6 states that "I wish we could give them by games... Children learn better with play, or they remember more with games. I think it can be given more easily with materials designed for games [game-based education]." The demonstration is the second teaching method that teachers mostly suggested. Five participants stated that demonstrative teaching should be applied in robotic education. For instance, T4 states that "We use demonstration. We first demonstrate than they imitate". Learning by doing is the third teaching method that teachers suggested for robotic education in kindergarten. Four participants stated that it will be a better method for this instruction. For example, T8 explained why s/he suggested this method as "I did not want to say what should be done to children...For instance I did not want to instruct saying 'turn it right' or 'left'. I did not want to limit the creativity of children". Moreover, two of the participants stated that robotic education should not be a separate course and it should be integrated with a curriculum and with a STEM perspective. One of the participants underlined that robotic education should be a one-to-one activity. Others suggested teaching methods/techniques which were: simple to complex ( $f=3$ ), using visuals $(f=3$ ), presentation ( $f=3$ ), group studies ( $f=2$ ), project-based learning ( $\mathrm{f}=2)$, brainstorming $(\mathrm{f}=1)$, drama $(\mathrm{f}=1)$, scaffolding $(\mathrm{f}=1)$.

Another sub-theme that emerged in data analysis was content. Most of the participants commented on the needed content of the ideal robotic education. They think that the content of robotic education should be enjoyable, game-based, and include visuals. For example, T1 states that "Content should be mostly visual. Children are illiterate, so they understand from pictures and visual elements". On the other hand, seven participants described the ideal 
material for robotic education when they ask to state their opinion about content. They described the needed teaching materials for robotic education under this sub-theme. Tangible and harmless materials were suggested by participants. One of the participants explained the proper material as "Since the children are preoperational, of course, tangible materials will be better. You can teach on paper, but kids will get bored after a while. So, I think it can be more permanent for children if teaching is done with concrete materials, robotic kits..."

The last sub-theme under the ideal robotic education theme was context. Description of the appropriate surroundings of the ideal robotic education in kindergarten is categorized under this sub-theme. Sitting plan, context features, context suggestions, and the number of children were the codes under this theme. In terms of the sitting plan, four of the participants stated that children should be placed face-to-face and children could see each other easily during the robotic class. Moreover, participants underlined that children should also see the demonstrations easily. For example, T3 describes the ideal place and states that "They can be sitting or standing. Because it can change according to the activities we will do. If possible, there should be environments where they can both sit and do it on the ground..." Moreover, participants underlined context features as a bright, flexible, and plain place. Besides, five participants stated that robotic education should be given in a different classroom designed for robotic education. For example, T7 described the ideal place in his words as "First of all, I think there should be an independent environment where the child can feel that they will do a different activity...so not in class. Some of our schools have practices in the form of a workshop". 2 of these participants also suggested that this workshop should be placed outside the kindergarten and children of different schools visit this workshop according to a schedule. Besides, one of the participants stated that this workshop should include all of the necessary materials. The last code under this sub-theme was the number of students. Only two of the participants make suggestions about the number of children in an ideal robotic education class. One of them (T6) stated that "Once it shouldn't be too crowded. Especially in our group. So it shouldn't exceed 15 individuals. Some things should be done individually and in others, a non-crowded environment should be created for children". On the other hand, T9 agreed with the limitation in student number and also address willingness and stated that "If such training is to be given, it should be based on volunteering ... Of course, others may come, but the number of children should be small for this education ...".

\section{Discussion and Conclusions}

The findings of this study demonstrate the perception of early childhood education (ECE) teachers about the status of kindergartens concerning robotic education, possible advantages / disadvantages of robotic education, and ideal robotic education. In this part, findings will be discussed with existing literature.

According to the results of this study, the first theme that emerged was the current situation of kindergarten for robotic education. First, the results showed that ECE teachers did not have experience with robotics but think that robotic education should be in early childhood education. Similarly, Piedade (2020) reported a high interest in primary and secondary school teachers in robotic education in Portugal. Another study showed Bulgarian, Greek, Croatian and Bosnian teachers', and parents' positive attitude to robotic education in primary schools (Musić, et. al, 2020). On the other hand, teachers also hesitated about using technology at an early age but there are technology-free robotic designs like the robotic prototype that Sullivan and Bers (2016) used in their study. Therefore, we may conclude that ECE teachers have positive attitudes to robotic education but with properly designed robotic kits for early 
childhood education, some hesitations may be eliminated.

Another result of this study related to the current status of kindergartens related to robotic education showed that there are many needs like teacher training, materials, curriculum, infrastructure, technical support, and parent education for implementing robotic education properly in kindergartens. First, results underlined that ECE teachers need training in robotic education. Teachers should know about robotics and it can be added to ECE programs in universities (Kucuk \& Sisman, 2018). Teachers' beliefs predicted the technology use of ECE teachers in their classroom (Blackwell, Lauricella, Wartella, Robb, \& Schomburg, 2013), and training teachers about robotic education may result in positive beliefs in technology. For example, according to an experimental study result, robotic education increased interest and self-efficiency to teach with robotic (Jaipal-Jamani \& Angeli, 2017). Hence, training both inservice and preservice ECE teachers about robotic may result in better robotic education in class and interest in using this technology in class. Second, there is a need for a proper curriculum and materials. The findings of this study showed that robotic education should be placed in the ECE curriculum and materials for this education should be provided by the education authority. Also, results showed that technical support, infrastructure, and parent education were the other needs of the teachers.

The second theme that emerged in this study showed that ECE teachers thought that there will be many advantages of robotic education for children. Among these advantages, motivation was the most emphasized possible positive effect of robotic education. Similarly, a qualitative study showed that robotic education at the tertiary level had positive effects on learner's intrinsic motivation (Apiola \& Tedre, 2013). Moreover, robotic education correlates positively with motivation (Aris \& Orcos, 2019) and affects the motivation of high school students positively (Marín-Marín, Costa, Moreno-Guerrero, \& López-Belmonte, 2020). Moreover, it increases motivation, devotion, and enjoyment at the primary level (Sáez-López, Sevillano-García, \& Vazquez-Cano, 2019). Other underlined possible advantages were related to knowledge, thinking skills, development, and psychomotor skills. Although there are limited experimental studies related to robotic education in the literature, some research results showed a significant increase in visual-spatial working memory, programming skills at the early childhood level (Di Lieto et al., 2017), computational thinking and creativity at the elementary level (Noh \& Lee, 2020), improve spatial ability in elementary level (Küçük \& Şişman, 2020), increase engineering interest of girls (aged 5-7)(Sullivan \& Bers, 2019), and though not significantly having the potential to increase cognitive and social skills (Ioannou \& Makridou, 2018). Moreover, according to observational study results, elementary students demonstrate creative behaviors during robotic activities (Nemiro, Larriva, \& Jawaharlal, 2017). However, another study showed no significant effect of robotic education on the achievement of pupils (Lindh \& Holgersson, 2007). These contrasting findings may be the result of small sample sizes and problematic experimental designs of research as Zhong and Xia (2020) criticized. Besides the advantages of robotic education, the findings of this study showed that the cost of the robotic kits, number of students in a class, and possible negative effects on socialization were the perceived negative effects of it. Similarly, Mariappan, Sing, and Nadaraj (2015) also criticized the cost of the robotic kits. To conclude, robotic education is generally considered positively and ECE teachers see great potential in this education. However, there should be inexpensive alternatives and solid research studies should be conducted to decide whether these perceived advantages are valid or not.

The last theme that emerged in this study was related to ideal robotic education and its features that was described clearly by ECE teachers. They underlined that in an ideal robotic 
education; teacher characteristics, teaching methods, content, and context were critical issues. In terms of teacher characteristics, findings showed that the teacher who will introduce robotics in kindergarten should have content knowledge about robotics. Studies show that teaching robotic in undergraduate ECE programs results positively in the self-efficiency of the teacher to use these kits in their classroom (Jaipal-Jamani \& Angeli, 2017). Besides teaching method was the other critical issue for the ideal robotic education. The result of this study revealed that suggested teaching strategy and techniques were teaching with games, demonstration, learning by doing, using visuals, simple-to-complex, group studies, projectbased learning, brainstorming, drama, and integrated curriculum. Similar to these findings in 21st Century Learning for Early Childhood Guide (2019) play-based learning, peer interaction, cooperative learning, combining learning domains were suggested to provide 21st-century learning for early childhood education. Also, another study underlined that the teaching method is an important issue in the quality of robotic education in elementary schools, and play-based and problem-based learning were better teaching methods for robotic education (Chootongchai, Songkram, \& Piromsopa, 2019).

For an ideal robotic education, ECE teachers suggest enjoyable content with a game-based design with visuals. Robotics provides an enjoyable learning environment for children (Sullivan \& Bers, 2019), and for a qualified robotic education, the content was an important factor (Chootongchai et al., 2019). Therefore, we may conclude that for better robotic education, there is a need for well-designed content. In ideal robotic education, context also has an important role. According to the results of this study, teachers suggested a face-to-face sitting plan. Moreover, they underlined that a bright, flexible, and simple learning environment would be better for robotic education. They also underlined that robotic education should be held in a different class like a laboratory with all the necessary equipment and the number of students should be limited. The results of this study also showed that in these settings, harmless and tangible materials should be provided to children. There are tangible and harmless versions developed by researchers (Mariappan et al., 2015; Sullivan \& Bers, 2016). However, there should be more research on alternative designs.

In conclusion, ECE teachers have a positive perception of robotic education. However, the current situation of kindergartens may be considered as insufficient. Teacher training, material, curriculum, and context were the stated aspects of needs underlined by ECE teachers. Therefore, a well-designed robotic education should be planned and delivered by answering these needs.

\section{Suggestions}

The results of this study showed for better robotic education activities in kindergartens, researchers and practitioners have many things to do. According to my findings, I provide some suggestions in the following lines.

\section{Suggestions for researchers}

- Potential benefits of robotic education for students should be evaluated in welldesigned experimental studies.

- Perspective of teachers about robotic education was analyzed by using a qualitative method in this study. For better generalizable results, the ECE teachers' perspective may be analyzed with quantitative methods. 
- Because of the qualitative nature of this study, perceptions of the other countries' ECE teachers about robotic education may vary. Hence, this study may be replicated in different countries.

\section{Suggestions for practitioners}

- Results of this study showed that there is a need for curriculum revision. Robotic education may be planned and included in the ECE curriculum.

- Results also showed that teachers need education about this topic. There can be planned training programs for in-service teachers and robotic education can be introduced to pre-service teachers in universities.

- Results showed that the context of education is considered as an important factor by teachers. Context design may be considered by policymakers. Also, due to the expensiveness of the robotic kits, these materials may be provided to schools for free.

\section{References}

Apiola, M., \& Tedre, M. (2013). Deepening Learning through Learning-by-Inventing. Journal of Information Technology Education: Innovations in Practice, 12, 185-202. https://doi.org/10.28945/1885.

Arís, N., \& Orcos, L. (2019). Educational Robotics in the Stage of Secondary Education: Empirical Study on Motivation and STEM Skills, Educational Sciences, 9(2).

Barak, M., \& Zadok, Y. (2009). Robotics projects and learning concepts in science, technology and problem solving. International Journal of Technology and Design Education. 19, 289-307. https://doi.org/10.1007/s10798-007-9043-3

Beisser, S. R. (2012). An examination of gender differences in elementary constructionist classrooms using lego/logo instruction. Classroom Integration of Type II Uses of Technology in Education. Computers in the Schools, 22 (3), 7-19. https://doi.org/10.1300/J025v22n03_02

Benitti, F. B. V. (2012). Exploring the educational potential of robotics in schools: A systematic review. Computers and Education, 58(3), 978-988. https://doi.org/10.1016/j.compedu.2011.10.006

Blackley, S., \& Howell, J. (2015). A STEM Narrative: 15 Years in the Making. Australian Journal of Teacher Education, 44(4), 51-64.

Blackwell, C. K., Lauricella, A. R., Wartella, E., Robb, M., \& Schomburg, R. (2013). Adoption and use of technology in early education: The interplay of extrinsic barriers and teacher attitudes. Computers and Education, 69, 310-319. https://doi.org/10.1016/j.compedu.2013.07.024

Bybee, R. W. (2010). What is STEM Education. Science, 329, 996. https://doi.org/10.1126/science.1194998

Cherniak, S., Lee, K., Cho, E., \& Jung, S. E. (2019). Child-identified problems and their robotic solutions. Journal of Early Childhood Research, 17(4), 347-360. https://doi.org/10.1177/1476718X19860557

Chootongchai, S., Songkram, N., \& Piromsopa, K. (2019). Dimensions of robotic education quality: teachers' perspectives as teaching assistants in Thai elementary schools. Education and Information Technologies. https://doi.org/10.1007/s10639-019-10041-1

Creswell, J. W. (2012). Educational research: Planning, conducting, and evaluating quantitative and qualitative research (4th Ed.). Boylston Street, Boston: Pearson.

Di Lieto, M. C., Inguaggiato, E., Castro, E., Cecchi, F., Cioni, G., Dell'Omo, M., ... Dario, P. (2017). Educational Robotics intervention on Executive Functions in preschool children: 
A pilot study. Computers in Human Behavior, 71, 16-23. https://doi.org/10.1016/j.chb.2017.01.018

Fayer, S., Lacey, A., \& Watson, A. (2017). STEM Occupations: Past, present, and future. Spotlight on Statistics, US Bureau of Labor Statistics, (January), 1-35. Retrieved from https://www.bls.gov/spotlight/2017/science-technology-engineering-and-mathematicsstem-occupations-past-present-and-future/pdf/science-technology-engineering-andmathematics-stem-occupations-past-present-andfuture.pdf\%0Ahttp://digitalcommons.ilr.cornell.

Fraenkel, J. R., Wallen, N. E., \& Hyun, H. H. (2015). How to design and evaluate research in education (9th Ed.). McGraw-Hill Education: NY.

Jaipal-Jamani, K., \& Angeli, C. (2017). Effect of Robotics on Elementary Preservice Teachers' Self-Efficacy, Science Learning, and Computational Thinking. Journal of Science Education and Technology, 26(2), 175-192. https://doi.org/10.1007/s10956-016-9663-z

Ioannou, A., \& Makridou, E. (2018). Exploring the potentials of educational robotics in the development of computational thinking: A summary of current research and practical proposal for future work. Education and Information Technologies, 23(6), 2531-2544. https://doi.org/10.1007/s10639-018-9729-Z

Jeong, H. I., \& Kim, Y. (2017). The acceptance of computer technology by teachers in early childhood education. Interactive Learning Environments, 25(4), 496-512. https://doi.org/10.1080/10494820.2016.1143376

Joo, Y. J., Park, S., \& Lim, E. (2018). Factors influencing preservice teachers' intention to use technology: TPACK, teacher self-efficacy, and Technology Acceptance Model. Educational Technology and Society, 21(3), 48-59.

Jung, S. E., \& Won, E. (2018). Systematic Review of Research Trends in Robotics Education for Young Children. Sustainability, 10(4), 905.

Kazakoff, E. R., \& Bers, M. U. (2014). Put Your Robot in, Put Your Robot out: Sequencing through Programming Robots in Early Childhood. Journal of Educational Computing Research, 50(4), 553-573. https://doi.org/10.2190/EC.50.4.f

Kucuk, S., \& Sisman, B. (2018). Pre-service teachers' experiences in learning robotics design and programming. Informatics in Education, 17(2), 301-320. https://doi.org/10.15388/infedu.2018.16

Sisman, B., Kucuk, S., \& Yaman, Y. (2020). The Effects of Robotics Training on Children's Spatial Ability and Attitude Toward STEM. International Journal of Social Robotics. https://doi.org/10.1007/s12369-020-00646-9

Lin, H. T., \& Kuo, T. H. (2010). Teaching programming technique with edutainment robot construction. In ICETC 2010 - 2010 2nd International Conference on Education Technology and Computer (Vol. 3). https://doi.org/10.1109/ICETC.2010.5529557

Lindh, J., \& Holgersson, T. (2007). Does lego training stimulate pupils' ability to solve logical problems? Computers and Education, 49(4), 1097-1111. https://doi.org/10.1016/j.compedu.2005.12.008

Manches, A., \& Plowman, L. (2017). Computing education in children's early years: A call for debate. British Journal of Educational Technology, 48(1), 191-201. https://doi.org/10.1111/bjet.12355

Mariappan, M., Sing, J. C., \& Nadarajan, M. (2015). A Design Methodology of Programmable Tangible Blocks for Early Childhood Educational Robotic System. Journal of Applied Sciences Research, 11, 17-25.

Marín-Marín, J. A., Costa, R. S., Moreno-Guerrero, A. J., \& López-Belmonte, J. (2020). Makey makey as an interactive robotic tool for high school students' learning in multicultural contexts. Education Sciences, 10(9), 1-14. https://doi.org/10.3390/educsci10090239

Mazman Akar, S. G. (2019). Does it matter being innovative: Teachers' technology acceptance. Education and Information Technologies, 24(6), 3415-3432. https://doi.org/10.1007/s10639-019-09933-z 
Mubin, O., Stevens, C. J., Shahid, S., Mahmud, A. Al, \& Dong, J.-J. (2013). a Review of the Applicability of Robots in Education. Technology for Education and Learning, 1(1). https://doi.org/10.2316/journal.209.2013.1.209-0015

Musić, J., Bonković, M., Kružić, S., Marasović, T., Papić, V., Kostova, S., ... Pachidis, T. (2020). Robotics and information technologies in education: four countries from Alpe-AdriaDanube Region survey. International Journal of Technology and Design Education. https://doi.org/10.1007/s10798-020-09631-9

Nemiro, J., Larriva, C., \& Jawaharlal, M. (2017). Developing Creative Behavior in Elementary School Students with Robotics. Journal of Creative Behavior, 51(1), 70-90. https://doi.org/10.1002/jocb.87

Noh, J., \& Lee, J. (2020). Effects of robotics programming on the computational thinking and creativity of elementary school students. Educational Technology Research and Development, 68(1), 463-484. https://doi.org/10.1007/s11423-019-09708-w

Piedade, J. M. N. (2020). Pre-service and in-service teachers' interest, knowledge, and selfconfidence in using educational robotics in learning activities. Educação \& Formação, 6(1). https://doi.org/10.25053/redufor.v6i1.3345

Reeves, T. C., \& Reeves, P. M. (2015). Reorienting educational technology research from things to problems. Learning Research and Practice, 1(1), 91-93.

Sáez-López, J. M., Sevillano-García, M. L., \& Vazquez-Cano, E. (2019). The effect of programming on primary school students' mathematical and scientific understanding: educational use of mBot. Educational Technology Research and Development, 67(6), 1405-1425. https://doi.org/10.1007/s11423-019-09648-5

Sohn, W.-S. (2014). Design and Evaluation of Computer Programming Education Strategy using Arduino. Advanced Science and Technology Letters, 66, 73-77. https://doi.org/10.14257/astl.2014.66.18

Sullivan, A., \& Bers, M. U. (2016). Robotics in the early childhood classroom: learning outcomes from an 8-week robotics curriculum in pre-kindergarten through second grade. International Journal of Technology and Design Education, 26(1), 3-20. https://doi.org/10.1007/s10798-015-9304-5

Sullivan, A., \& Bers, M. U. (2019). Investigating the use of robotics to increase girls' interest in engineering during early elementary school. International Journal of Technology and Design Education, 29(5), 1033-1051. https://doi.org/10.1007/s10798-018-9483-y

Sullivan, F. R. (2008). Robotics and science literacy: Thinking skills, science process skills and systems understanding. Journal of Research in Science Teaching, 45(3), 373-394. https://doi.org/10.1002/tea.20238

Taylor, M. S., Vasquez, E., \& Donehower, C. (2017). Computer Programming with Early Elementary Students with Down Syndrome. Journal of Special Education Technology, 32(3), 149-159. https://doi.org/10.1177/0162643417704439

Wong, G. K. W. (2016). The behavioral intentions of Hong Kong primary teachers in adopting educational technology. Educational Technology Research and Development, 64, 313338. https://doi.org/10.1007/s11423-016-9426-9

Yıldırım, A. \& Şimşek, H. (2016). Sosyal bilimlerde nitel araştırma yöntemleri (10th Ed.). Seçkin Pubs: Ankara.

Zhong, B., \& Xia, L. (2020). A Systematic Review on Exploring the Potential of Educational Robotics in Mathematics Education. International Journal of Science and Mathematics Education, 18(1), 79-101. https://doi.org/10.1007/s10763-018-09939-y

21st Century Learning for Early Childhood Guide. (2019). Retrieved November 18, 2020, from http://static.battelleforkids.org/documents/p21/P21EarlyChildhoodGuide.pdf 